\title{
Non-isothermal Decomposition Kinetics of a New High-energy Organic Potassium Salt: K(DNDZ)
}

\author{
Kangzhen Xu, ${ }^{*}$ Fengqi Zhao,,${ }^{+*}$ Jirong Song, ${ }^{\ddagger}$ Xiaolei Ren, Hongxu Gao, ${ }^{\star}$ Siyu $\mathrm{Xu}^{\dagger}{ }^{\dagger}$ and Rongzu $\mathrm{Hu}^{\dagger}$ \\ Department of Chemical Engineering, Northwest Lniversitv, Ii'an 710069 P. R. China. ${ }^{*}$ E-mail xukzanu'u.educh \\ Xi'an Modern Chemistry Research Institute, Ii an 710065. P. R. China. 'E-mail: zhaofqiâl63.com \\ "Conservation Technologv Department, the Palace Huseum, Beijing 100009, P. R. China \\ Received June 19. 2009. Accepted August 13. 2009
}

\begin{abstract}
A new high-energy organic potassium salt, 2-(dinitromethylene)-1,3-diazepentane potassium salt K(DNDZ), was synthesized by reacting of 2-(dinitromethylene)-1,3-diazepentane (DNDZ) and potassium hydroxide. The thermal behavior and non-isothermal decomposition kinetics of $\mathrm{K}(\mathrm{DNDZ})$ were studied with DSC, TG/DTG methods. The kinetic equation is $\frac{\mathrm{d} \alpha}{\mathrm{d} T}=\frac{10^{13.92}}{\beta} 3(1-\alpha)[-\ln (1-\alpha)]^{\frac{2}{3}} \exp \left(-1.52 \times 10^{5} / R T\right)$. The critical temperature of thermal explosion of $\mathrm{K}(\mathrm{DNDZ})$ is $208.63^{\circ} \mathrm{C}$. The specific heat capacity of $\mathrm{K}(\mathrm{DNDZ})$ was determined with a micro-DSC method, and the molar heat capacity is $224.63 \mathrm{~J} \mathrm{~mol}^{-1} \mathrm{~K}^{-1}$ at $298.15 \mathrm{~K}$. Adiabatic time-to-explosion of $\mathrm{K}$ (DNDZ) obtained is $157.96 \mathrm{~s}$.
\end{abstract}

Key Words: 1,1-Diamino-2.2-dinitroetlyylene (FOX-7). 2-(Dinitromethylene)-1.3-diazepentane (DNDZ), Non-isothermal decomposition kinetics. Specific heat capacity. Adiabatic time-to-explosion

\section{Introduction}

1.1-Diamino-2.2-dinitroethylene (FOX-7) is a novel highenergy material with high thermal stability and low sensitivity to impact and friction. When first synthesized in $1998,{ }^{1}$ FOX-7 received much attention. Many researches have been carried out on the synthesis. mechanism, molecular structure. thermal behavior. explosive performance and application of FOX- 7$\rangle^{-1}$ ?

"Push-pull" nitro-enamine is a kind of compound with special construction which possesses a highly polarized carbon-carbon double bond with positive and negative charges being stabilized by the amino group and nitro group respectively. and exists in manifold tautomers and resonances. ${ }^{18} \mathrm{FOX}-7$ is a representative "push-pull" nitro-enamine compound. FOX-7 presents certain acidic properties and can react with some nucleophiles to syn-

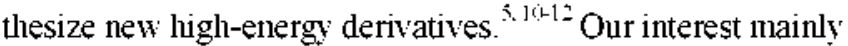
consisted in modifying molecular structure of FOX -7 in order to obtain some new high-energy compounds and research their structure-property relationship. ${ }^{19-2-2}$

We prepared a derivative of FOX-7.2-(dinitrometlyylene)1.3-diazepentane (DNDZ), and found it still belongs to "pushpull" nitro-enanine contpound, has the same characteristics to FOX-7 and exists in many manifold tautomers and resonances (Scheme 1) ${ }^{19}$ It can also react with strong alkalis (KOH). and we have used it to prepare a new high-energy organic potassium salt (Scheme 2), which will be used as flame suppressor in propellant to substitute inorganic potassium salt $\left(\mathrm{KCl}_{2} \mathrm{~K}_{2} \mathrm{SO}_{4}, \mathrm{KNO}_{3}\right.$ and $\mathrm{K}_{3} \mathrm{AlF}_{6}$ ) to generate much more energy and clean gas.

In this paper. we studied the decomposition kinetic behavior of K(DNDZ) under non-isothermal conditions by DSC. TG/<smiles>CC1CNC(=C([N+](=O)[O-])[N+](=O)[O-])N1</smiles>

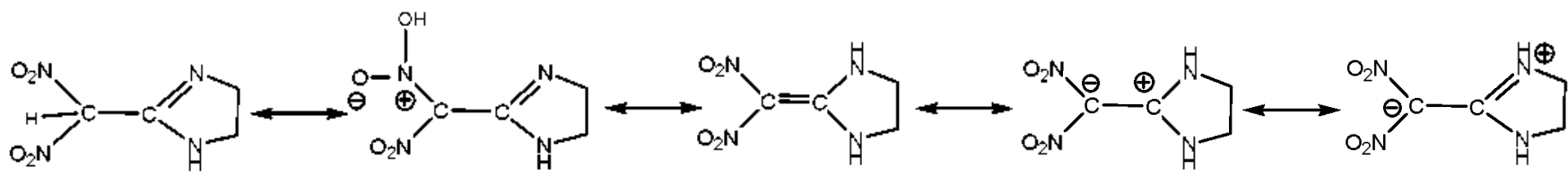

Scheme 1. Tautomers and resonances of DNDZ.<smiles></smiles>

FOX-7<smiles>NCCN</smiles><smiles>CC1=C([N+](=O)[O-])NCC1</smiles>

DNDZ

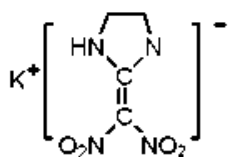

K(DNDZ)

Scheme 2. Synthesis of K(DNDZ). 
DTG methods. determined the specific heat capacity with a micro-DSC method and calculated the adiabatic time-to-explosion for further estimating the themmal stability of K(DNDZ).

\section{Experimental}

Sample. K(DNDZ) was prepared as follows: DNDZ (1.74 g) was suspended in $10 \mathrm{~mL}$ of water and to it a solution of $\mathrm{KOH}$ ( $1.12 \mathrm{~g}$ in $4 \mathrm{~mL}$ of water) was added drop wise. After reaction at room temperature for $20 \mathrm{~min} .25 \mathrm{~mL}$ of methanol were also

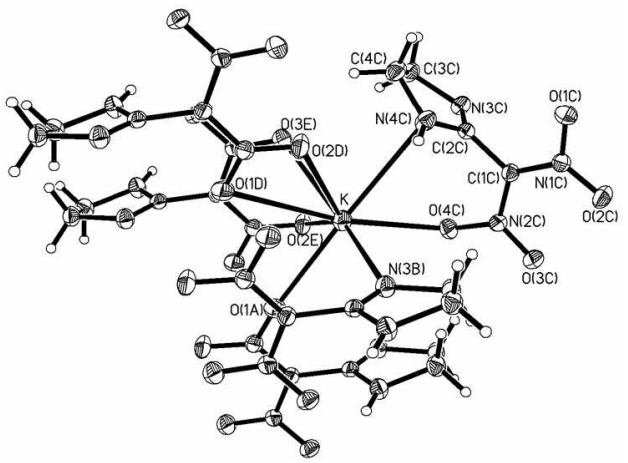

Figure 1. Crystal structure of K(DNDZ).

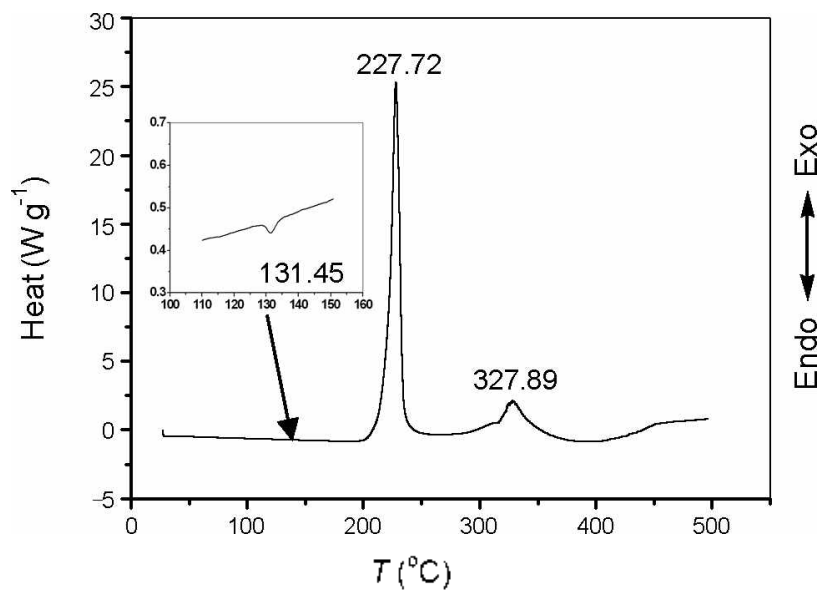

Figure 2. DSC curve of K(DNDZ).

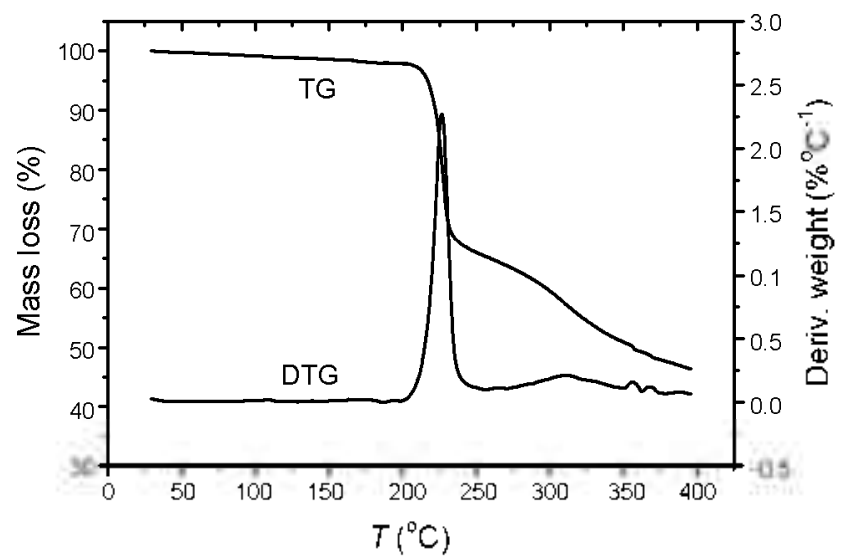

Figure 3. TG/DTG curves of $\mathrm{K}(\mathrm{DNDZ})$ at a heating rate of $10.0^{\circ} \mathrm{C}$ $\mathrm{min}^{-1}$. added drop wise. and the resulting mixture was slowly cooled to $0^{\circ} \mathrm{C}$. Many bright yellow crystals of $\mathrm{K}(\mathrm{DNDZ})$ were formed. which were filtered. washed with methanol and dried under vacuunt. yielding $1.51 \mathrm{~g}(71 \%)$. Anal. Calcd. $(\%)$ for $\mathrm{C}_{4} \mathrm{H}_{3} \mathrm{~N}_{4} \mathrm{O}_{4} \mathrm{~K}$ : $\mathrm{C} 17.39 . \mathrm{H}$ 4.39. $\mathrm{N} 47.33$; found: $\mathrm{C} 17.46 . \mathrm{H} 4.38, \mathrm{~N}$ 46.63. The characteristic peaks of IR (KBr) are: $3317,2972.2866 .1622$, $1511,1475,1438,1361,1278,1226,1097 \mathrm{~cm}^{-1}$. The molecular structure is shown in Figure 1.

Experimental Equipments and Conditions. The DSC experiments for K(DNDZ) were perfonned using a DSC-Q200 apparatus (TA, USA) under a nitrogen atmosphere at a flow rate of $50 \mathrm{~mL} \mathrm{~min} \mathrm{~min}^{-1}$ and the amount of used sample was about $1 \mathrm{mg}$. The heating rates used were $2.0,5.0,10.0$ and $20.0^{\circ} \mathrm{C} \mathrm{nuin}^{-1}$ from ambient temperature to $500.0^{\circ} \mathrm{C}$.

The TG/DTG experiment for K(DNDZ) was perfonmed using a SDT-Q600 apparatus (TA. USA) under a nitrogen atmosphere at a flow rate of $100 \mathrm{~mL} \mathrm{~min}^{-1}$. The amount of used sample was about $1 \mathrm{mg}$. The heating rate used was $10.0^{\circ} \mathrm{C} \mathrm{min}^{-1}$ from ambient temperature to $400.0^{\circ} \mathrm{C}$.

The specific heat capacity $\left(C_{\mathrm{F}}\right)$ of $\mathrm{K}(\mathrm{DNDZ})$ was deternuned using a Micro-DSC III apparatus (SETARAM, France). the amount of used sample was $393.73 \mathrm{mg}$. The heating rate used was $0.15^{\circ} \mathrm{C}$ nin ${ }^{.}$from 10.0 to $80.0^{\circ} \mathrm{C}$.

\section{Results and Discussion}

Themal Behavior: The typical DSC and TG/DTG curves (Figures 2 and 3) indicate that K(DNDZ) has no melting point. and its thennal behavior can be divided into two obvious exothernic decomposition stages. The first stage occurs at 180 $240^{\circ} \mathrm{C}$ with a mass loss of about $35 \%$ and the extrapolated onset temperature. peak temperature and decomposition enthalpy are $220.43^{\circ} \mathrm{C} .227 .72^{\circ} \mathrm{C}$ and $1832.5 \mathrm{~J} \mathrm{~g}^{. l}$ at the heating rate of $10.0^{\circ} \mathrm{C} \mathrm{min}^{-1}$. respectively. The second stage occurs at $240 \sim$ $360^{\circ} \mathrm{C}$ with a mass loss of about $18 \%$. and the extrapolated onset temperature. peak temperature and enthalpy are $316.83^{\circ} \mathrm{C}$. $327.89^{\circ} \mathrm{C}$ and $637.13 \mathrm{Jg}^{.}$at the heating rate of $10.0^{\circ} \mathrm{C} \mathrm{min}{ }^{.1}$. respectively. But. there is still a very unconspicuous crystal phase transition process. The peak temperature and enthalpy of the crystal phase transition are $131.45^{\circ} \mathrm{C}$ and $1.923 \mathrm{~J} \mathrm{~g}^{-1}$ at the heating rate of $2.5^{\circ} \mathrm{C} \mathrm{min}^{-1}$. All are very different from that of DNDZ whose thermal behavior has only one intense exothernuc decomposition process. and the extrapolated onset temperature and peak temperature are 256.64 and $267.60^{\circ} \mathrm{C}$ at the heating rate of $10.0^{\circ} \mathrm{C} \mathrm{min}^{-1}$. $^{15} \mathrm{~K}(\mathrm{DNDZ})$ has lower thernal stability than $\mathrm{DNDZ}$.

Non-isothemmal Decomposition Kinetics. In order to obtain the kinetic parameters (the apparent activation energy $(E)$ and pre-exponential constant (A)) of the two exothermic decomposition reactions for $\mathrm{K}(\mathrm{DNDZ})$, a multiple heating method (Kissinger method ${ }^{23}$ and Ozawa method ${ }^{24}$ ) was employed (Figure 4). The Kissinger and Ozawa equations are as follows:

$$
\begin{aligned}
& \ln \left(\frac{\beta}{T_{\mathrm{p}}^{2}}\right)=\ln \frac{A R}{E}-\frac{E}{R} \frac{1}{T_{\mathrm{p}}} \\
& \log \beta+\frac{0.4567 E}{R T_{\mathrm{p}}}=C
\end{aligned}
$$


where $T_{p}$ is the peak temperature $(\mathrm{K}) . \beta$ is the linear heating rate $\left({ }^{\circ} \mathrm{C} \mathrm{min}{ }^{-1}\right), E$ is the apparent activation energy $\left(\mathrm{kJ} \mathrm{mol}^{-\mathrm{l}}\right)$. $A$ is the pre-exponential constant $\left(\mathrm{s}^{-1}\right), R$ is the gas constant ( $\mathrm{J}$ $\mathrm{mol}^{-1} \mathrm{~K}^{-1}$ ) and $C$ is a constant.

The measured values of the beginning temperature $\left(T_{0}\right)$. extrapolated onset temperature $\left(T_{b}\right)$. peak temperature $\left(T_{p}\right)$ and enthalpy $\left(\Delta H_{3}\right.$ ) of the two exothermic decomposition reactions were listed in Table 1. The above-mentioned values ( $E$ and $A$ ) determined by Kissinger method and Ozawa method and the linear correlation coefficients $(r)$ are listed in Table 2

From Table 2. we can see that the apparent activation energy obtained by Kissinger method agrees well with that obtained by Ozawa method. moreover. the linear correlation coefficients are all very close to 1 . So. the result is credible. Moreover the apparent activation energy of the first exothermic decomposition reaction was low, indicating that $\mathrm{K}(\mathrm{DNDZ})$ is easy to decompose at temperature above $180^{\circ} \mathrm{C}$.

$T$ versus $a$ (the conversion degree) curves at different heating rates [Thermal decomposition data of K(DNDZ) by DSC curves] were shown in Figure 5. By substituting corresponding data $\left(\beta_{1}\right.$. $T_{i}$ and $\left.\alpha_{i}, i=1,2,3, \cdots\right)$ into $\mathrm{Eq}$. (2). the values of $E$ for ary given value of $\alpha$ were obtained and shown in Figure 6 . We can see that the values of $E$ steadily distribute from 139 to $150 \mathrm{~kJ} \mathrm{~mol}^{-1}$ in the $\alpha$ range of $0.0125 \sim 0.95$, and the average value of $E$ is $142.78 \mathrm{~kJ} \mathrm{~mol}^{-3}$. which is in approximate agreement with that obtained by Kissinger method and Ozawa method from only peak-temperature values. So the values were used to check the validity of $E$ by other methods.

The integral Eqs. (3)-(7) are cited to obtained the values of

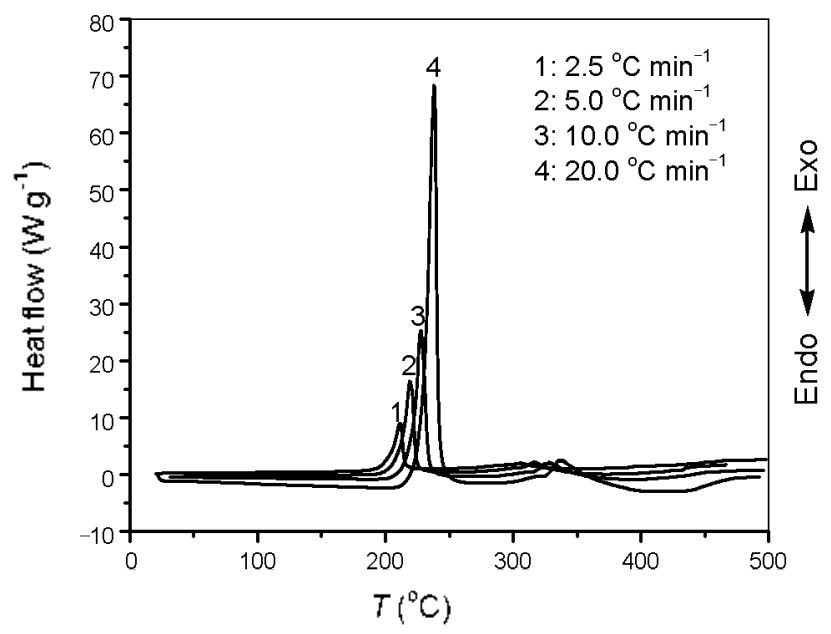

Figure 4. DSC curves of K(DNDZ) at various heating rates.
$E, A$ and the most probable kinetic model function $(f(\alpha))$ from each single DSC curve. ${ }^{25}$

The general integral equation ${ }^{2}$ :

$$
\ln \left[\frac{G(\alpha)}{T^{2}\left(1-\frac{2 R T}{E}\right)}\right]=\ln \left(\frac{A R}{\beta E}\right)-\frac{E}{R T}
$$

The universal integral equation ${ }^{27}$ :

$$
\ln \left[\frac{G(\alpha)}{T-T_{0}}\right]=\ln \frac{A}{\beta}-\frac{E}{R T}
$$

MacCallum-Tanner equation 28

$$
\begin{aligned}
\log [G(\alpha)]= & \log \left[\frac{A E}{\beta R}\right]-0.4828 E^{0.497} \\
& -\frac{0.449+0.217 E}{0.001} \frac{1}{T}
\end{aligned}
$$

Satava-Sesták equation ${ }^{2}$ :

$$
\log [G(\alpha)]=\log \left[\frac{A E}{\beta R}\right]-2.315-0.4567 \frac{E}{R T}
$$

Agrawal equation ${ }^{3 i !}$ :

$$
\ln \left[\frac{G(\alpha)}{T^{2}}\right]=\ln \left\{\frac{A R}{\beta E}\left[\frac{1-2\left(\frac{R T}{E}\right)}{1-5\left(\frac{R T}{E}\right)}\right]\right\}-\frac{E}{R T}
$$

where $G(\alpha)$ is the integral model function, $T$ is the absolute temperature $(\mathrm{K}), E$ is the activation energy $\left(\mathrm{kJ} \mathrm{mol}^{-1}\right) . \beta$ is the linear heating rate $\left(\mathrm{K} \mathrm{min}^{-1}\right), R$ is the gas constant $\left(\mathrm{J} \mathrm{mol}^{-1} \mathrm{~K}^{-1}\right)$.

Table 2. Kinetic parameters obtained by the data in Table 1 .

\begin{tabular}{|c|c|c|c|c|c|c|c|}
\hline \multirow{2}{*}{$\begin{array}{c}\beta \\
\left({ }^{\circ} \mathrm{C} \text { minn }^{-1}\right)\end{array}$} & \multicolumn{4}{|c|}{ The first stage } & \multicolumn{3}{|c|}{ The second stage } \\
\hline & $T_{1,}\left({ }^{\circ} \mathrm{C}\right)$ & $T_{e}\left({ }^{n} \mathrm{C}\right)$ & $T_{\mathrm{T}}\left({ }^{\circ} \mathrm{C}\right)$ & $\Delta H_{\mathrm{d}}\left(\mathrm{k}^{-\mathrm{T}} \mathrm{mol}^{-1}\right)$ & $T_{e}(\mathrm{C} \mathrm{C})$ & $T_{\mathrm{p}}\left({ }^{\circ} \mathrm{C}\right)$ & $\Delta H_{\mathrm{d}}\left(\mathrm{kJ} \mathrm{mol}^{-1}\right)$ \\
\hline 2.5 & 182.39 & 203.13 & 211.39 & & 292.14 & 306.10 & \\
\hline 5.0 & 189.21 & 211.76 & 219.26 & & 304.01 & 316.44 & \\
\hline 10.0 & 194.51 & 220.43 & 227.72 & 388.89 & 316.83 & 327.89 & 135.21 \\
\hline 20.0 & 205.19 & 229.31 & 238.17 & & 324.50 & 337.76 & \\
\hline
\end{tabular}

\begin{tabular}{lcccccc}
\hline & $\begin{array}{c}E_{\mathrm{k}} \\
\left(\mathrm{kJ} \mathrm{mol}^{-1}\right)\end{array}$ & $\begin{array}{l}\log A_{\mathrm{k}} \\
\left(A_{\mathrm{k}}, \mathrm{s}^{-1}\right)\end{array}$ & $n_{\mathrm{k}}$ & $\begin{array}{c}E_{0} \\
\left(\mathrm{~kJ} \mathrm{~mol}^{-1}\right)\end{array}$ & $r_{\mathrm{o}}$ \\
\hline The first stage & 152.0 & 13.92 & 0.9985 & 152.4 & 0.9987 \\
The second stage & 181.5 & 13.80 & 0.9993 & 182.0 & 0.9994 \\
\hline
\end{tabular}

${ }^{a}$ Subscript $k$ is data obtained by Kissinger's method. Subscript $O$ is data obtained by Ozawa s method.

Table 1. The measured values of $T_{0}, T_{\mathrm{e}}, T_{\mathrm{p}}$ and $\Delta H_{\mathrm{d}}$ of the two esothermic decomposition stages for K(DNDZ) from the DSC curves at various heating rates $(\beta)$. 


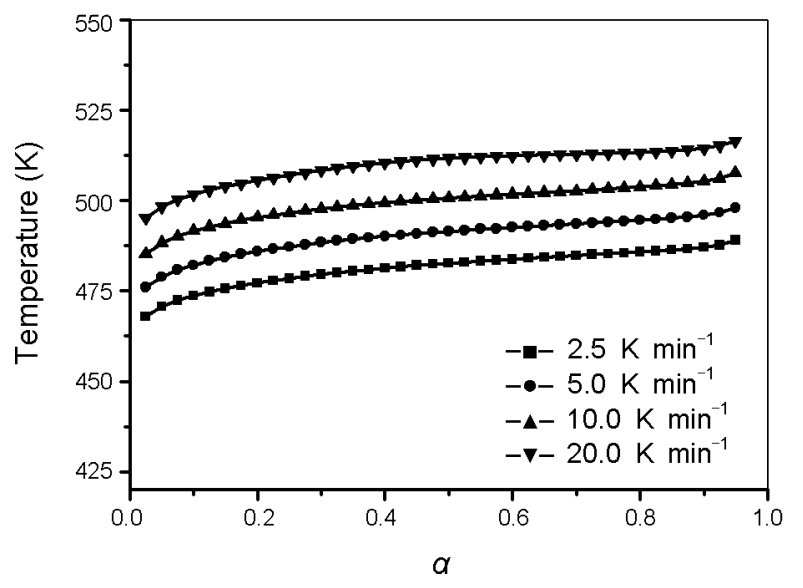

Figure 5. $T$ vs $\sigma$ curves for the decomposition reaction of K(DNDZ) at different heat rates.

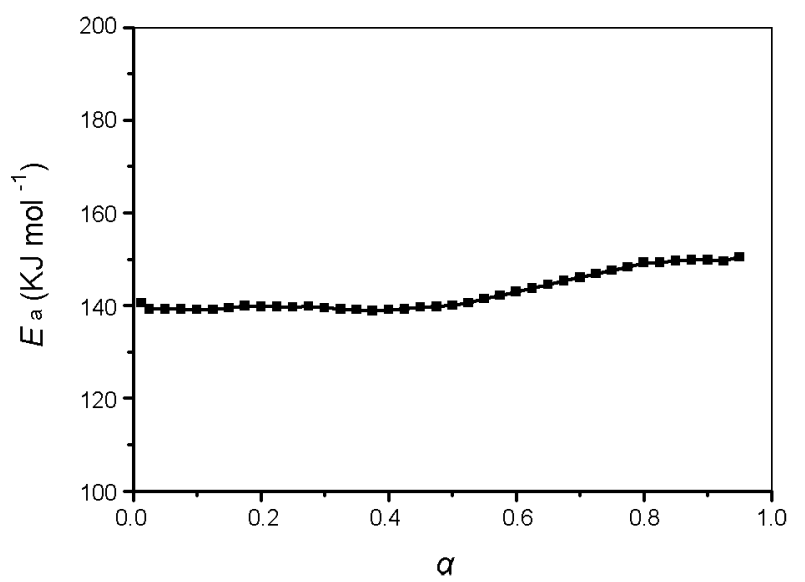

Figure 6. $E_{\mathrm{a}}$ 's a curve for the decomposition reaction of $\mathrm{K}(\mathrm{DNDZ})$ by Ozawa's method.

and $\alpha$ is the conversion degree.

Forty-one types of kinetic model functions in Ref. [25] and corresponding experimental data form DSC curves at different heating rates were put into Eqs. (3)-(7) for calculating, respectively. The kinetic parameters ( $E$ and $A$ ). probable kinetic model function and linear conrelation coefficient $(r)$ are presented in Table 3. We can see that their values of $E$ and $\log A$ obtained by the five equations agree well with each other. especially to small heating rates, and the mean value is close to that obtained by Kissinger method and Ozawa method. So. we can conclude that the most probable kinetic model function of the first exothermic decomposition reaction of $\mathrm{K}(\mathrm{DNDZ})$ is classified as $f(\alpha)=3(1-\alpha)[-\ln (1-\alpha)]^{\frac{\hat{2}}{2}}$, Avrami-Erofeev equation (No. 11). and $G(\alpha)=[-\ln (1-\alpha)]^{\frac{1}{3}}$, according to the unanimity rule of calculation results to each model equation. So the kinetic equation of the exothermic decomposition reaction can be described as ${ }^{35}$ :

$$
\begin{aligned}
\frac{\mathrm{d} \alpha}{\mathrm{d} T}= & \frac{10^{12.92}}{\beta} 3(1-\alpha)[-\ln (1-\alpha)]^{\frac{2}{3}} \\
& \times \exp \left(-1.52 \times 10^{3} / R T\right)
\end{aligned}
$$

Table 3. Calculated values of kinetic parameters of decomposition

\begin{tabular}{|c|c|c|c|c|c|}
\hline $\begin{array}{c}\beta \\
\left(\mathrm{K} \mathrm{min}^{-1}\right)\end{array}$ & $\mathrm{Eq}$. & No. & $\begin{array}{c}E \\
\left(\mathrm{~kJ} \mathrm{~mol}^{-1}\right)\end{array}$ & $\begin{array}{l}\log A \\
\left(A, \mathrm{~s}^{-1}\right)\end{array}$ & $r$ \\
\hline \multirow[t]{5}{*}{2.5} & 4 & 11 & 137.70 & 12.36 & 0.9982 \\
\hline & 5 & 11 & 141.67 & 11.23 & 0.9983 \\
\hline & 6 & 11 & 138.03 & 12.33 & 0.9984 \\
\hline & 7 & 11 & 138.50 & 12.43 & 0.9983 \\
\hline & 8 & 11 & 137.69 & 12.36 & 0.9982 \\
\hline \multirow[t]{5}{*}{5.0} & 4 & 11 & 137.15 & 12.32 & 0.9977 \\
\hline & 5 & 11 & 141.19 & 11.20 & 0.9978 \\
\hline & 6 & 11 & 137.61 & 12.31 & 0.9979 \\
\hline & 7 & 11 & 138.11 & 12.41 & 0.9979 \\
\hline & 8 & 11 & 137.15 & 12.32 & 0.9977 \\
\hline \multirow[t]{5}{*}{100} & 4 & 11 & 142.90 & 12.95 & 0.9979 \\
\hline & 5 & 11 & 147.03 & 11.82 & 0.9980 \\
\hline & 6 & 11 & 143.57 & 12.96 & 0.9981 \\
\hline & 7 & 11 & 143.73 & 13.03 & 0.9981 \\
\hline & 8 & 11 & 142.90 & 12.94 & 0.9979 \\
\hline \multirow[t]{5}{*}{20.0} & 4 & 11 & 149.27 & 13.60 & 0.9858 \\
\hline & 5 & 11 & 153.47 & 12.46 & 0.9866 \\
\hline & 6 & 11 & 150.14 & 13.64 & 0.9873 \\
\hline & 7 & 11 & 149.94 & 13.66 & 0.9872 \\
\hline & 8 & 11 & 149.27 & 13.60 & 0.9858 \\
\hline & mean & & 142.85 & 12.60 & \\
\hline
\end{tabular}
reaction for $\mathrm{K}(\mathrm{DNDZ})$.

The values of $T_{(\mathrm{w},} T_{\left.\mathrm{e}^{1}\right)}$ and $T_{\left.\mathrm{p}^{\prime}\right)}$ in the first exothermic decomposition stage corresponding to $\beta \rightarrow 0$ obtained by Eq. (9) are 178.36. 195.95 and $204.87^{\circ} \mathrm{C}^{25}$

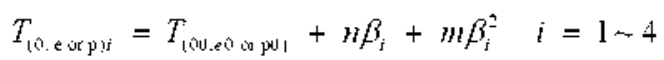

where $n$ and $m$ are coefficients.

The critical temperature of thermal explosion ( $T_{b}$ ) obtained by Eq. (10) was $208.63^{\circ} \mathrm{C}^{25.31}$ which is lower than that of DNDZ as $261.04^{\circ} \mathrm{C}^{19}$

$$
T_{\mathrm{b}}=\frac{E_{\mathrm{o}}-\sqrt{E_{\mathrm{u}}^{2}-4 E_{0} R T_{\mathrm{eu}}}}{2 R}
$$

where $E_{01}$ is the apparent activation energy obtained by Ozawa's method.

Specific Heat Capacity of K(DNDZ). Figure 7 shows the determination results of $\mathrm{K}(\mathrm{DNDZ})$. using a continuous specific heat capacity mode of Micro-DSC III. In deternined temperature range. specific heat capacity presents a good quadratic relationship with tenperature. Specific heat capacity equation of $\mathrm{K}$ (DNDZ) is:

$$
\begin{aligned}
& C_{\mathrm{f}}\left(\mathrm{J} \mathrm{g}^{-1} \mathrm{~K}^{-1}\right)=-0.7957+9.4028 \times 10^{-3} T \\
& -1.0679 \times 10^{-5} T^{2}(283.0 \mathrm{~K}<T<353.0 \mathrm{~K})
\end{aligned}
$$

The molar heat capacity of $\mathrm{K}(\mathrm{DNDZ})$ is $224.63 \mathrm{~J} \mathrm{~mol}^{-1} \mathrm{~K}^{-1}$ at $298.15 \mathrm{~K}$. Although only $70 \mathrm{~K}$ range was taken in the determi- 


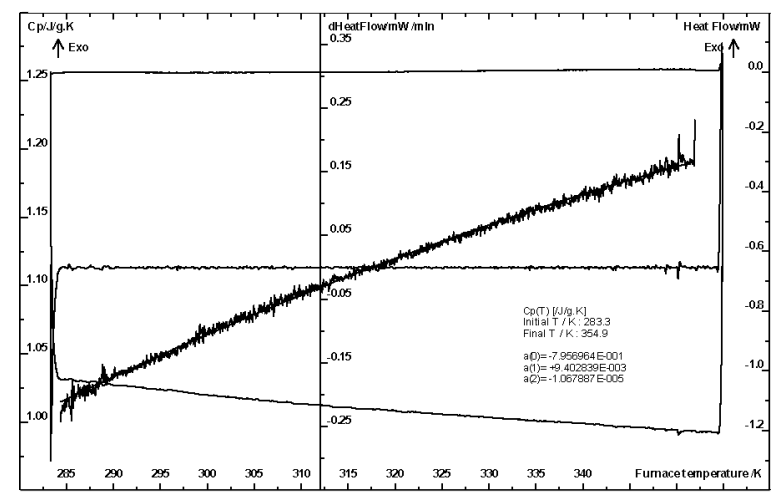

Figure 7. Deternination results of the continuous specific heat capacity of $\mathrm{K}(\mathrm{DNDZ})$.

ning process the specific heat capacity equation obtained is a stable and continuous equation. which can provide a reference and some help for the wide temperature applications.

Adiabatic Time-to-explosion of K(DNDZ). Energetic materials need a time from the beginuing thermal decomposition to thermal explosion in the adiabatic condition. We called the time as the adiabatic time-to-explosion. ${ }^{-3 *-35}$ Ordinarily. the heating rate $(\mathrm{d} T / \mathrm{d} t)$ and critical heating rate $(\mathrm{d} T / \mathrm{d} r)_{\pi}$ were used to evaluate the thermal stability of energetic materials in adiabatic decomposition process. However, we can calculate the adiabatic time-to-explosion $(t)$ by the following Eqs. (12) - (13) when we have obtained a series of experimental data. ${ }^{2.53 .35}$ Thereby. as an important parameter. it is very easy and intuitive to directly evaluate the thermal stability of energetic materials according to the length of the adiabatic time-to-explosion.

$$
\begin{aligned}
& C_{p} \frac{\mathrm{d} T}{\mathrm{~d} t}=Q A \exp (-E / R T) f(\alpha) \\
& \alpha=\int_{\tau_{\mathrm{n}}}^{\tau} \frac{C_{\mathrm{p}}}{Q} \mathrm{~d} T
\end{aligned}
$$

where $C_{\text {p }}$ is the specific heat capacity $\left(\mathrm{J} \mathrm{mol}^{-1} \mathrm{~K}^{\cdot l}\right) . T$ is the absolute temperature $(\mathrm{K}), t$ is the adiabatic time-to-explosion (s). $O$ is the exothermic values $\left(\mathrm{J} \mathrm{mol}^{-1}\right), A$ is the pre-exponential factor $\left(\mathrm{s}^{-1}\right) . E$ is the apparent activation energy of the thermal decomposition reaction $\left(\mathrm{J} \mathrm{mol}^{-1}\right), R$ is the gas constant $\left(\mathrm{J} \mathrm{mol}^{-1}\right.$ $\left.\mathrm{K}^{-1}\right), f(\alpha)$ is the most probable kinetic model function and $\alpha$ is the conversion degree

The combination of Eqs. (12) - (13) gives the following equation:

$$
t=\int_{0}^{1} \mathrm{~d} t=\int_{T ;}^{T} \frac{C_{\mathrm{p}} \exp (E / R T)}{Q .1 f(\alpha)} \mathrm{d} T
$$

The limit of the temperature integration in $\mathrm{Eq} .(14)$ is from $T_{\mathrm{b} 0}$ to $T_{\mathrm{b}}$. So. we can directly get $t=157.96 \mathrm{~s}$ from Eq. (14). according to the above experimental results. This is a short time. and can be proved credible according to the change of DSC curve in the first exothermic decomposition stage. The time is also shorter than that of DNDZ as a certain value between 263 $290 \mathrm{~s}$. In another aspect. it further proves the lower thermal stability of $\mathrm{K}(\mathrm{DNDZ})$ than that of $\mathrm{DNDZ}$.

\section{Conclusion}

(1) The thermal decomposition reaction kinetics of K(DNDZ) was studied under the non-isothermal conditions by DSC and TG/DTG methods. and the kinetic equation of the exothermic obtained is $\frac{\mathrm{d} \alpha}{\mathrm{d} T}=\frac{10^{13.92}}{\beta} 3(1-\alpha)[-\ln (1-\alpha)]^{\frac{2}{3}} \exp (-1.52 \times$ $10^{5} / R T$ ). The critical temperature of thermal explosion is $208.63^{\circ} \mathrm{C}$.

(2) Specific heat capacity equation of $\mathrm{K}(\mathrm{DNDZ})$ is $\mathrm{C}_{\mathrm{F}}\left(\mathrm{J} \mathrm{g}^{-1}\right.$ $\left.\mathrm{K}^{.1}\right)=-0.7957+9.4028 \times 10^{-2} T-1.0679 \times 10^{-5} \times T^{2}(283.0 \mathrm{~K}<$ $T<353.0 \mathrm{~K}$ ), and the molar heat capacity is $224.63 \mathrm{~J} \mathrm{~mol}^{-1} \mathrm{~K}^{-1}$ at $298.15 \mathrm{~K}$. The adiabatic time-to-explosion of K(DNDZ) was calculated to be $157.96 \mathrm{~s}$. K(DNDZ) is easy to decompose at temperature above $180^{\circ} \mathrm{C}$.

Ackmowledgments. This investigation received financial assistance front the National Natural Science Foundation of China (20803085). the Natural Science Foundation of Shaanxi Province (SJ08B10). the National Defense Key Laboratory of Propellant and Explosive Combustion of China (9140C3503010905) and NWU Graduate Experiment Research Funds (08YSY 19).

Appendix A. Supplementary Material. Crystallo-graphic data for K(DNDZ) have been deposited in the Cambridge Crystallographic Data Center as supplementary publications (CCDC mumber 675360).

\section{Refelences}

1. Latypov, N. V.; Bergman, T.; Langlet, A.; Wellmar, U.; Bemm, U. Tetrahedron $1998,5 \% 11525$.

2. Gindulyte, A.; Massa, L.; Huang, L.; Karle, J. J. Phus. Chem. A 1999. 103,11045

3. Sorescu, D. C.; Boatz, J. A.; Thopmson, D. L. J. Phys. Chent A $2001,105,5010$.

4. Ji, G. F.; Xiao, H. M.; Dong, H. S.; Gong, X. D.; Li, T. S.; Wang, Z. Y. Acta Chm Sinica 2001, 59,39.

5. Bellamy, A. J.; Goede, P.; Sandberg, C. Latypow, N. V. The Proceedings of the 33 th Intentional Amual Conference ICT, Karlsruke, Germany, 2002.

6. Sorescu, D. C.; Boatz, J. A.; Thompson, D. L. J. Phys. Chent. B 2003, 107,8953 .

7. Cai, H. Q.: Shu, Y. J.; Yu, W. F.: Li, I. S.; Cheng, B. B. Acta Chim. Sinica 2004, 62, 295.

8. Gao, H. X.; Zhao, F. Q.; Hu, R. Z.; Pan, Q.: Wang, B. Z.; Yang. X. W. Gao, Y.: Gao, S. L.: Shi, Q. Z. Chin. J. Chem 2006. 2t. 177 .

9. Hervé, G.; Jacob, G.; Latypov, N. Tetrahedron 2005, 61, 6743.

10. Anniyappan, M.; Talawar, M. B.; Gore, G. M.: Venugopalan, S.; Gandhe, B. R. J. Hazard Mater. 2006, 137, 812 .

11. Trzciŕski, W. A.; Cudzilo, S.; Chylek, Z.; Szymańczyk, L. $J$. Hozorl ilater: 2008, 157,605.

12. Zerilli, F. T.; Kuklja, M. M. J. Phys. Chemt .4 2007,111, 1721

13. Hervé, G.; Tacob, G.: Laty pov, N. Tetrohedron 2007, 63, 953.

14. Majano, G.; Mintova, S.; Bein, T.; Klapötke, T. M. J. PHys. Chent. C 2007, 111, 6694

15. Latypov, N. V; Johansson, M:; Holmgren, E; Sizova, E. V:; Sizov, V. V.; Bellamy, A. T. Org. Process Res. Dev 2007, 11, 56.

16. Fan, X. Z.: Li, J. Z.: Lill, Z. R. J. Phus Chem A 2007, 111, 13291.

17. Buszewski, B.: Michel, M.; Cudzilo, S.: Chylek, Z. J. Hazard Mater. 2009, 164, 1051

18. Rajappa. S. Tetahedron 1981, 37, 1453

19. Xu, K. Z.; Song, I. R.; Yang, X.: Chang.C. R.: Yang, X. K.; Ma, 
H. X; Huang, J.: Zhao, F. Q. J. Mole. Strt. 2008, 891, 340.

20. Chang, C. R.: Xu, K. Z.: Song, J. R.: Yan, B.; Ma, H. X.: Gao, H. X. Zhao, F. Q. Acta Chim. Simica 2008, 66, 1399.

21. Xu, K. Z.; Chang, C. R.; Song, J. R.; Zhao, F. Q: Ma, H. X.; Lv, X. Q: Hu, R. Z. Chin. J. Chem. 2008, 26, 495.

22. Xu, K. Z;; Song, T. R,; Zhao, F. Q.: Heng, S. Y.; Ding, L.; Wang, Y. Y: Hu, R. Z. J. Chim. Chem. Soc. 2009, 56, 524 .

23. Kissinger, H. E. Anal Chem 1957, 29, 1702.

24. Ozawa, T. Bull. Chem. Soc. Jph. 1965, 38, 1881 .

25. Hu, R. Z: Gao, S. L.; Zhao, F. Q. Shi, Q. Z.; Zhang, T. L.; Zhang, I. J. Themal Anatvsis Kinetics $\left(2^{\mathrm{th}}\right)$; Science Press: Beijing, 2008 .

26. Caot, A. W: Redfen, J. P. Nature 1964, 201(4914), 68.

27. Hu, R. Z: Yang, Z. Q.; Ling, Y. J. Thermochm .4cta 1988, 123 ,
135

28. MacCallum, J. R.: Tanner, I. Em: Ploymer J. 1968, f, 333.

29. Satava, F.: Sestak, I. J. Them. Anal 1975, 8, 477.

30. Agrawal, R. K. J. Them . Anal. 1987, $32,149$.

31. Zhang, T. L.; Hu, R. Z ; Xie, Y.; Li, F. P. Themochim. Acta 1994, $2+4,171$.

32. Smith, L. C. Themochim. Acta 1975. 13.1

33. Xu, K. Z; Song, T. R.; Zhao, F. Q; Cao, Z. H.; Ma, H. X: Hu, R. Z.; Gao, H. X:- Huang, J. Acta Chim. Sinica 2007, 65, 2827.

34. Xu, K. Z: Song, I. R.; Zhao, F. Q.: Ma, H. X.; Gao, H. X.; Chang, C. R.: Ren, Y. H.: Hu, R. Z. J. Hazard Mater. 2008, 158, 333.

35. Xu, K. Z; Zhao, F. Q; Song, J. R.; Chang, C. R.; Li, M.; Wang, Y. Y.; Hu, R. Z. Chin. J. Chent 2009, 27,665. 